\title{
ANNOUNCEMENT
}

\section{PHYSICAL CHEMISTRY AND HYDRODYNAMICS LEVICH BIRTHDAY CONFERENCE}

Will be held in Somerville College, Oxford, England, on 11-13 July 1977, in celebration of the 60th Birthday of:

\section{Professor Benjamin LeVich}

Conference Committee Chairman: Sir Derek Barton F.R.S., Nobel Laureate.

The subject is Physicochemical Hydrodynamics and related topics in Physical Chemistry and Hydrodynamics', special emphasis being given to developments arising from Professor Levich's work. Individual sessions will be devoted to some or all of the topics covered by the chapter heatings of Professor Levich's well-known 1962 book:

Convective diffusion in liquids,

Diffusion rates in turbulent flow,

Heat transfer in fluids,

Problems in the theory of coagulation of dispersions involving liquids and gases,

Passage of current through electrolytic solutions,

Motion induced by capillarity,

Motion of drops and bubbles in fluid media,

Motion of particles in electrolytic solutions,

Theory of the polarographic method,

Waves on a liquid surface,

Motion and diffusion in thin liquid films.

Review lectures on world-wide developments in the various fields since the 1960's will be presented by leading experts. Shorter Contributions will also be presented and included in the Proceedings. Papers will be preprinted, in time for the meeting, by Hemisphere Publishing Corporation, which will publish the final Proceedings. It is hoped that Professor Levich will himself be able to attend and to deliver a lecture.

Persons interested in Presenting a paper should note that contributions have to be:

(a) submitted to D. Brian Spalding (address below) in abstract form, for acceptance in principle;

(b) submitted as typescripts on standard paper (supplied by Hemisphere Publishing Corporation) for refereeing:

(c) corrected, if accepted, and

(d) submitted to Hemisphere Publishing Corporation for printing, in corrected typescript form;

By 1 March 1977. Contributions which do not meet this deadline are welcome and will be considered for presentation. They will not, however, be included in the Preprints circulated at the Conference but will be included in the Final Proceedings.

Persons interested in attending the Conference should write to: The Levich Conference Organizer, Professor D. Brian Spalding, Imperial College of Science \& Technology, Mechanical Engineering Department, Exhibition Road, London SW7 2AZ, England. 